\title{
EFFECT OF INTRAPERITONEAL BUPIVACAINE ON POSTOPERATIVE PAIN IN LAPAROSCOPIC GYNAECOLOGICAL SURGERY-A RANDOMISED CONTROLLED TRIAL
}

\author{
Pradipta Kumar Patel1, Santosh Kumar Dora², Benudhar Pande 3 \\ ${ }^{1}$ Associate Professor, Department of Anaesthesia, VIMSAR, Burla, Odisha. \\ ${ }^{2}$ Assistant Professor, Department of Obstetrics and Gynaecology, VIMSAR, Burla, Odisha. \\ ${ }^{3}$ Assistant Professor, Department of Obstetrics and Gynaecology, VIMSAR, Burla, Odisha.
}

\section{ABSTRACT}

\section{BACKGROUND}

Postoperative management of pain has always been challenging as more and more patients are undergoing minimal invasive surgery with patients discharged on day care basis. The objective of the study is to evaluate the effect of intraperitoneal infiltration of Bupivacaine over pain score and total analgesic requirement in patients undergoing gynaecological laparoscopic surgery.

\section{MATERIALS AND METHODS}

Two hundred and fifty women undergoing laparoscopic gynaecology surgery were randomised to receive intraperitoneal infiltration of Bupivacaine or normal saline postoperatively. Visual Analogue Score (VAS) was calculated at 1, 2, 4, 8, 12 and 24 hours of surgery. All patients were given Paracetamol infusion 1 gram as and when required in both the groups. A total dose of analgesic requirements in last 24 hours were calculated for both the groups. Since the study duration was short, we had to limit the sample size for convenience.

\section{RESULTS}

Patients with Bupivacaine group compared with Normal saline, there is a statistically significant less VAS score ( $p$ value $<0.005)$ at $1,2,4,8,12$ and 24 hours of surgery. When both the groups were compared in terms of total analgesic requirements in first 24 hours, there was statistically significant ( $p$ value $<0.001$ ) less analgesics requirement in bupivacaine group. We did not find any postoperative complication in Bupivacaine group compared to Normal saline group.

\section{CONCLUSION}

In laparoscopic gynaecological surgery, use of intraperitoneal Bupivacaine effectively reduces pain score and analgesic requirement in immediate postoperative period.

\section{KEYWORDS}

Bupivacaine, Intraperitoneal Analgesics, Laparoscopy.

HOW TO CITE THIS ARTICLE: Patel PK, Dora SK, Pande B. Effect of intraperitoneal bupivacaine on postoperative pain in laparoscopic gynaecological surgery- a randomised controlled trial. J. Evolution Med. Dent. Sci. 2018;7(10):1209-1211, DOI: $10.14260 /$ jemds/2018/276

\section{BACKGROUND}

Postoperative management of pain is one of the major challenges since decades. Early postop pain management will lead to early ambulation, early recovery and also lead to decreased incidence of deep vein thrombosis. To reduce postop pain, laparoscopy has evolved over the laparotomy as a major alternative due to its equal or better outcomes. To reduce pain after surgery, local infiltration of local anaesthetic agent has been used in both surgical and gynaecological patients.1,2 One systematic analysis and review concluded the use of local anaesthetic agents in gynaecological surgery patients reduces postoperative pain effectively. 3 Despite its usefulness for pain reduction, controversy still exists in its usefulness. ${ }^{4,5}$

'Financial or Other Competing Interest': None.

Submission 12-02-2018, Peer Review 22-02-2018,

Acceptance 26-02-2018, Published 05-03-2018.

Corresponding Author:

Dr. Santosh Kumar Dora,

Assistant Professor,

Department of Obstetrics and Gynaecology,

VIMSAR, Burla,

Odisha, India

E-mail: santoshdora1@gmail.com

DOI: $10.14260 /$ jemds $/ 2018 / 276$

\section{(c) $(1) \Theta$}

The objective of this study is to evaluate the effect of intraperitoneal bupivacaine versus normal saline in laparoscopic benign gynaecologic surgery on postoperative pain score and total analgesic requirement in a tertiary care hospital.

\section{MATERIALS AND METHODS}

A prospective, randomised, double-blinded trial was conducted at VIMSAR and Samleswari Hospital, Burla, Odisha. A total of 250 patients admitted in the above hospital for laparoscopic gynaecological surgeries were recruited between Jan 2016 and Jan 2018. All patients were informed about the study protocol and those who agreed to participate, a written informed consent were taken. All patients fulfilling the criteria for inclusion were included in the study. A total of 125 patients in each group were recruited. Lottery method was used for randomisation to select the first group out of the two groups. Subsequently, the cases were allocated by systematic randomised allocation method. The study was approved by the Institutional Ethics Committee. Patients with age $\geq 18$ years, benign adnexal lesions (ovarian cyst, endometriotic cyst, hydrosalpinx, tubal ligation), hysterectomy (Fibroid, adenomyosis, abnormal uterine bleeding not responding to medical treatment), American Society of Anesthesiologists (ASA) score 1 or 2 requiring laparoscopic surgery were included in this study. Women 
with known allergy to Bupivacaine and Paracetamol, chronic renal failure and those with peritoneal drain after surgery were excluded from the study. Relevant patient's information was entered on a predesigned proforma. A detailed physical examination and relevant preoperative laboratory investigations were done.

A single surgeon and anaesthetist have performed all the surgeries. Pre-anaesthetic check-up of all patients were done. Patients were explained about the visual analogue score (VAS) of $1-10$, where 1 denotes no pain and number 10 denotes worst pain. Surgeries were performed under general anaesthesia. All women admitted to the above hospital for laparoscopic gynaecological surgery were randomised to receive intraperitoneal instillation of $30 \mathrm{~mL}$ of $0.25 \%$ Bupivacaine, maximum dose not exceeding $2 \mathrm{mg} / \mathrm{kg}$ (study group) at the port site or $30 \mathrm{~mL}$ of normal saline as placebo (control group) after the completion of surgery. Once patients respond to verbal commands VAS score was calculated after $1,2,4,8,12$ and 24 hours of surgery. All patients were given Paracetamol infusion 1 gram as and when required. A total dose of analgesic requirements in last 24 hours were calculated for both the groups. Since the study duration was short, we had to limit the sample size for convenience.

The primary outcome of the study was postoperative pain, which was assessed by the VAS. The secondary outcomes were operating time (initial incision to skin closure), estimated blood loss, change in haemoglobin level (from before the surgery to the first postoperative day), additional analgesic requirements and perioperative complications were noted.

Statistical analysis- All statistical analyses were done using SPSS version 24 (IBM) and Microsoft Excel 2016 for windows. Significance test was done with independent sample t-test. Results were obtained as mean \pm standard deviation. A ' $p$ ' value of $<0.05$ was considered statistically significant.

\section{RESULTS}

A total of 250 patients were recruited for this study, comprising 125 patients in each Bupivacaine and Normal saline group. Bupivacaine or normal saline is infiltrated according to the randomisation table. The mean age, body mass index, duration of surgery, duration of anaesthesia and mean blood loss between Bupivacaine and Normal saline group were $39.6 \pm 13.9$ and $35.8 \pm 13.1,21.5 \pm 5.1$ and $22.6 \pm$ $8.6,58.50 \pm 5.28$ and $57.79 \pm 4.33,70.10 \pm 5.28$ and $72.39 \pm$ $4.80,25 \pm 10.73$ and $35 \pm 15.53$ respectively with no significant difference between them. In Bupivacaine group 80 (64\%), $33(26.4 \%)$ and $12(9.6 \%)$ number of patients had hysterectomy, ovarian cystectomy and tubal ligation respectively. In normal saline group 59 (47.2\%), 39 (31.2\%) and 27 (21.6\%) number of patients had hysterectomy, ovarian cystectomy and tubal ligation respectively. All these information are detailed in Table 1 . The median pain score reported as VAS score and total analgesic requirements for both Bupivacaine and Normal saline group is tabulated in Table 2. There is a statistically significant reduction of pain reported by patients and analgesics requirement in Bupivacaine group compared to saline group. The details of VAS score at 1 hr., 2 hrs., 4 hrs., 8 hrs., 12 hrs. and 24 hrs. in Bupivacaine group and normal saline is described in Table 2 with ' $p$ ' value of $<0.005$. The total analgesics requirement in
Bupivacaine and Normal saline groups are $0.67 \pm 0.55$ and $2.37 \pm 0.68$ grams respectively with a p-value of 0.001 . The median first requirement of analgesia in Bupivacaine group is $11 \pm 2.28$ hours compared to $1 \pm 0.58$ hours in normal saline group with a ' $p$ ' value of 0.000 . No side effects observed in both the study and control groups were noted at $1 \mathrm{hr}$., $2 \mathrm{hrs}$., 4 hrs., 8 hrs., 12 hrs. and 24 hrs. due to infiltration of either Bupivacaine or Normal saline.

\begin{tabular}{|c|c|c|}
\hline $\begin{array}{c}\text { Demographic } \\
\text { Profile }\end{array}$ & $\begin{array}{c}\text { Bupivacaine } \\
\text { Group (n=125) }\end{array}$ & $\begin{array}{c}\text { Normal Saline } \\
\text { Group (n=125) }\end{array}$ \\
\hline Age & $39.6 \pm 13.9$ & $35.8 \pm 13.1$ \\
\hline Body Mass Index & $21.5 \pm 5.1$ & $22.6 \pm 8.6$ \\
\hline $\begin{array}{c}\text { Duration of Surgery } \\
\text { in Minutes }\end{array}$ & $58.50 \pm 5.28$ & $57.79 \pm 4.33$ \\
\hline $\begin{array}{c}\text { Duration of } \\
\text { Anaesthesia in } \\
\text { Minutes }\end{array}$ & $70.10 \pm 5.28$ & $72.39 \pm 4.80$ \\
\hline $\begin{array}{c}\text { Estimated Blood } \\
\text { Loss (mL) }\end{array}$ & $25 \pm 10.73$ & $35 \pm 15.53$ \\
\hline Hysterectomy & $80(64 \%)$ & $59(47.2 \%)$ \\
\hline Ovarian Cystectomy & $33(26.4 \%)$ & $39(31.2 \%)$ \\
\hline Tubal Ligation & $12(9.6 \%)$ & $27(21.6 \%)$ \\
\hline \multicolumn{2}{|c|}{ Table 1. Patient's Profile in Study and Control Group } \\
\hline
\end{tabular}

\begin{tabular}{|c|c|c|c|}
\hline VAS Score & $\begin{array}{c}\text { Bupivacaine } \\
\text { Group }\end{array}$ & $\begin{array}{c}\text { Normal Saline } \\
\text { Group }\end{array}$ & P-value \\
\hline $1 \mathrm{hr}$. & $1.70 \pm 1.86$ & $4.50 \pm 1.96$ & 0.000 \\
\hline $2 \mathrm{hrs}$. & $2.93 \pm 2.99$ & $4.93 \pm 2.49$ & 0.000 \\
\hline $4 \mathrm{hrs}$. & $2.87 \pm 2.76$ & $4.87 \pm 2.56$ & 0.000 \\
\hline $8 \mathrm{hrs}$. & $3.47 \pm 1.17$ & $5.57 \pm 1.47$ & 0.002 \\
\hline $12 \mathrm{hrs}$. & $3.77 \pm 2.76$ & $5.77 \pm 2.16$ & 0.001 \\
\hline $24 \mathrm{hrs}$. & $3.67 \pm 2.96$ & $5.57 \pm 2.56$ & 0.001 \\
\hline $\begin{array}{c}\text { Total analgesic } \\
\text { requirement } \\
\text { in 24 hrs. in } \\
\text { grams }\end{array}$ & $0.67 \pm 0.55$ & $2.37 \pm 0.68$ & 0.001 \\
\hline \multicolumn{3}{|l|}{ Table 2. VAS Score between Study and Control Group } \\
\hline
\end{tabular}

\section{DISCUSSION}

Adequate management of postoperative pain is the new challenge in the modern surgical practice due to more and more patients prefer minimal invasive surgery over traditional surgery and many of them are getting discharged on the same day. Local peritoneal infiltration of local anaesthetics over the incision site reduces the nociceptive sensation from the visceral peritoneum which will decrease the total requirement of analgesia, but there is a controversy regarding the timing of infiltration of local anaesthetic agent.6,7 Mark et al conducted a systematic analysis where they found that postoperative infiltration of local anaesthetic in laparoscopic gynaecologic surgery is effective in controlling post-op pain, though the pain score at 24 hours was similar. We have also observed similar results in our patients and infiltration of Bupivacaine is more effective than placebo (normal saline). Another study showed that the use of Ropivacaine at port site and intraperitoneum resulted in decreased pain and opioid usage in benign gynaecological surgical patients. ${ }^{8}$ The reported effect of intraperitoneal local anaesthetics has been mixed in the gynaecologic literature. In a literature review many authors have used intraperitoneal infiltration of Ropivacaine, Bupivacaine with MgSO4 with decreased pain in the study group compared to the control group. ${ }^{8,9}$ We have also arrived at similar conclusion with 
Bupivacaine. Another study by Catenacci SS et al compared nebulisation with instillation of Ropivacaine at the time of laparoscopic ovarian cystectomy. ${ }^{10}$ Nebulisation with Ropivacaine was associated with a higher proportion of patients reporting a numeric pain score of 3 or less within the first 4 hours of surgery $(\mathrm{p}<.05)$ and a lower proportion of patients requiring narcotics ( $82 \%$ vs. $96 \%, \mathrm{p}<.05)$ without a difference in mean amount of morphine used or length of hospital stay.

The median difference in total dose of analgesics between the two groups was 2 grams without any statistically significant difference in side effects. However, side effects such as nausea, GI bleeding, skin rash and constipation can occur after a single dose of analgesic, a decrease of even 1 - 2 dose of analgesics administration may improve patient's comfort and satisfaction. Besides bupivacaine is rarely associated with any side effects except used during an epidural anaesthesia, and in our study there were no differences in cardiopulmonary complication rates between the two groups. This study has several limitations worth noting. It was a single institution study and all surgeries were performed by a team of one surgeon and an anaesthetist, which may limit the generalisability of the present findings. However, this may be viewed as strength of this study, since there are fewer variations such as differences in surgical techniques between different institutions or surgeons, and also provided reliability of outcomes with consistency. As pain is a subjective finding, patient self-reporting is the best indicator of pain. Thus, this study deliberately used individual patient's pain assessment to act as their own control.

\section{Limitations}

Since the study duration was short, we had to limit the sample size for convenience.

\section{CONCLUSION}

Our study showed that the administration of intraperitoneal Bupivacaine was associated with decreased postoperative analgesic use and a trend toward decreased patient-reported pain scores in patients undergoing minimally invasive surgery. Further studies using a wide range of gynaecologic surgeons may add generalisability to the study procedures and further authenticate our observations.

\section{REFERENCES}

[1] El-Sherbiny W, Saber W, Askalany AN, et al. Effect of intra-abdominal instillation of lidocaine during minor laparoscopic procedures. Int J Gynaecol Obstet 2009;106(3):213-5.
[2] Kahokehr A, Sammour T, Zargar SK, et al. Intraperitoneal local anesthetic improves recovery after colon resection: a double-blinded randomized controlled trial. Ann Surg 2011;254(1):28-38.

[3] Marks JL, Ata B, Tulandi T. Systematic review and metaanalysis of intraperitoneal instillation of local anesthetics for reduction of pain after gynecologic laparoscopy. J Minim Invasive Gynecol 2012;19(5):545-53.

[4] Sherwinter DA, Ghaznavi AM, Spinner D, et al. Continuous infusion of intraperitoneal bupivacaine after laparoscopic surgery: a randomized controlled trial. Obes Surg 2008;18(12):1581-6.

[5] Rodriguez L, Pardal BC, Castro GA, et al. Intraperitoneal analgesia compared with levobupivacaine $0.25 \%$ versus saline in laparoscopic bariatric surgery: 14AP5-11. Eur J Anaesthesiol 2011;28:203.

[6] Gvozdenović L, Cvijanović R, Kolak R, et al. Anaesthesiology in current world of laparoscopic surgery. Med Danas 2003;2:298-301.

[7] Paulson J, Mellinger J, Baguley W. The use of intraperitoneal bupivacaine to decrease the length of stay in elective laparoscopic cholecystectomy patients. Am Surg 2003;69(4):275-8.

[8] Cruz JJ, Diebolder H, Dogan A, et al. Combination of pre-emptive port-site and intraoperative intraperitoneal ropivocaine for reduction of postoperative pain: a prospective cohort study. Eur J Obstet Gynaecol Reprod Biol 2014;179:11-6.

[9] Yadava A, Rajput SK, Katiyar S, et al. A comparison of intraperitoneal bupivacaine-tramadol with bupivacaine-magnesium sulphate for pain relief after laparoscopic cholecystectomy: a prospective, randomised study. Indian J Anaesth 2016;60(10):75762.

[10] Catenacci SS, Lovisari F, Peng S, et al. Postoperative analgesia after laparoscopic ovarian cyst resection: double blind multicenter randomized control trial comparing intraperitoneal nebulization and peritoneal instillation of ropivacaine. J Minim Invasive Gynecol 2015;22(5):759-66. 